\title{
UPCT-Bloopbusters: Teaching Science and Technology through Movie Scenes and related Experiments
}

\author{
Rodríguez, José-Víctor ${ }^{\mathrm{a}}$; Castro-Rodríguez, Enrique ${ }^{\mathrm{b}}$; Sánchez-Pérez Juan-Francisco ${ }^{\mathrm{b}}$ \\ and Serrano-Martínez, José-Luis ${ }^{c}$
}

${ }^{a}$ Departament of Information Technologies and Communications, Universidad Politécnica de Cartagena, Spain, ${ }^{b}$ Department of Applied Physics, Universidad Politécnica de Cartagena, Spain 'Department of Mining, Geological and Cartographic Engineering, Universidad Politécnica de Cartagena, Spain.

\begin{abstract}
In order to change the preconceptions of youth towards science and technology subjects (which, usually, are perceived as difficult or boring), new educational methods aimed at motivating and engaging students in learning are becoming more and more necessary. In this sense, an educational project called 'UPCT-Bloopbusters' through which a group of professors of the Universidad Politécnica de Cartagena (UPCT), Spain, use science fiction movie scenes - as well as experiments- within the lecture room to teach both physics and engineering technology is hereby presented. The methodology of the project is properly described and the results of a survey carried out among the students of a course in which such methodology has been used are shown. In view of this survey, it can be concluded that the project has been more than welcome by the students while at the same time has favored the learning of a great deal of physics and technology concepts.
\end{abstract}

Keywords: Teaching of science; Educational innovation; Science fiction. 
UPCT-Bloopbusters: Teaching Science and Technology through Scene Movies and related Experiments

\section{Introduction}

How to change the preconceptions of students towards science and technology subjects (which, usually, are perceived as difficult or boring) is always a challenge for science educators. In this sense, the use of science fiction movies can be a powerful resource within the lecture room to help students motivate and engage in their learning of different science disciplines (Franknoi, 2002; Rose, 2003; Barnett et al., 2006; Bixler, 2007; Frieden \& Elliot, 2007; Blasco et al., 2010; Blasco et al., 2011). Specifically, when it comes to teaching physics or engineering, the use of science fiction movie scenes can represent an interesting complementary methodology to illustrate how (or how not) the laws of physics of our universe behave, while at the same time having fun (Asimov, 1968; Everitt \& Patterson, 1999; Chandler, 2002; Daley, 2004; Dark, 2005; Berne \& Schummer, 2005). Furthermore, it should be noted that, through science fiction movies, students not familiarized with scientific fields can be stimulated so that new scientific and technological vocations may be awaked (Smith, 2009).

In this work, the educational project called 'UPCT-Bloopbusters' through which a group of professors of the Universidad Politécnica de Cartagena (UPCT), Spain, use science fiction movie scenes within the classroom to teach both physics and engineering technology is hereby presented. This methodology has also been used/shown by such professors in different events such as Science and Technology Week celebrations or film festivals. Moreover, UPCT-Bloopbusters is an initiative from the Unit of Scientific Culture and Innovation of the UPCT which counts on the collaboration of the Fundación Española para la Ciencia y la Tecnología (FECYT) - Ministerio de Economía, Industria y Competitividad (MINECO), Spain.

\section{Methodology}

It is well known that, although science fiction movies are great for stimulating the mind and enjoying fantastic worlds, usually, fundamental errors are made within such movies regarding true science. Therefore, following the same philosophy already published throughout different books (Cavelos, 1999; Wolverton \& Stern, 2002; Kakalios, 2005; Rogers, 2007; Weiner, 2007), in the UPCT-Bloopbusters project, firstly, science fiction movie scenes -related to specific physical or technological matters to be taught- are shown in the classroom. Then, the students are invited to detect the errors that they think were made in the scene from a physics and technology point of view. Next, after an enriching debate, the professor clears up the students' questions not only by explaining the bases of the errors made along the movie scenes but also -different from other similar and inspiring educational projects (Palacios, 2007) - by performing attractive experiments by which the true physics underlying such errors is properly demonstrated. Finally, a series of 
problems related to the issues previously learnt are proposed to the students, who should solve them and discuss the solution.

This way, just to name a few examples, the impossibility of sound propagation along the vacuum of interstellar space is learnt through Star Wars battleship scenes in which noisy explosions are mistakenly heard (this fact is demonstrated with an alarm clock ringing inside a vacuum pump - Fig. 1), the fundamentals of radioactivity are properly taught through the scene from Indiana Jones and the Crystal Skull in which our hero incredibly survives a nuclear explosion inside a fridge, or the acceleration of gravity is discussed through a Spiderman scene in which the superhero catches the villain even when both are suffering the same free fall.

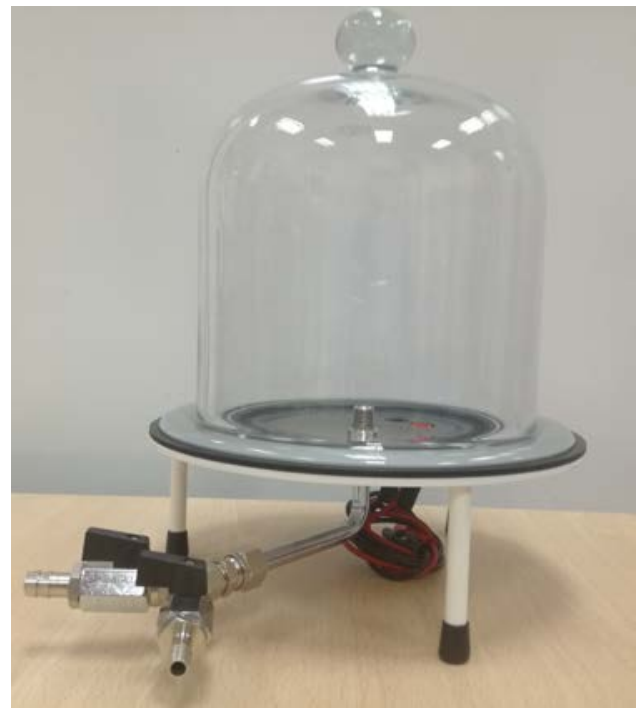

Figure 1. Vacuum pump used to demonstrate the impossibility of sound propagation in vacuum.

\section{Results}

A series of questions were asked to the students of a course (population: 54) in which the methodology of the professors from the UPCT-Bloopbusters project were used (course 2016/17, UPCT, Spain), in order to know their opinion about it. In this sense, the results of the three more relevant questions of the questionnaire are shown in Figs. 2 to 4 (where 5 represents the maximum level of satisfaction and DK/NR means Don't know/No reply). As can be observed, the methodology based on science fiction movie scenes as well as experiments was highly appreciated among the students. A huge majority (51 out of 54) 
UPCT-Bloopbusters: Teaching Science and Technology through Scene Movies and related Experiments

indicated that liked such way of teaching and the same amount affirmed that had learnt some new concepts with it, among which the following stand out: physics in general, propagation of sound, or the influence of the moon on Earth. In this sense, it should be mentioned that, since 51 out of 54 said that they had learnt some new concepts, the fact that 10 answered with a DK/NR to the question about what they had learnt (Fig. 4) could be explained by noting that all these responses were NR (not DK) and such fact points to the possibility of some kind of laziness from those students when it came to answer the only question that required writing rather than selecting a number or just the options 'yes' or 'no'.

What do you think about this teaching methodology?

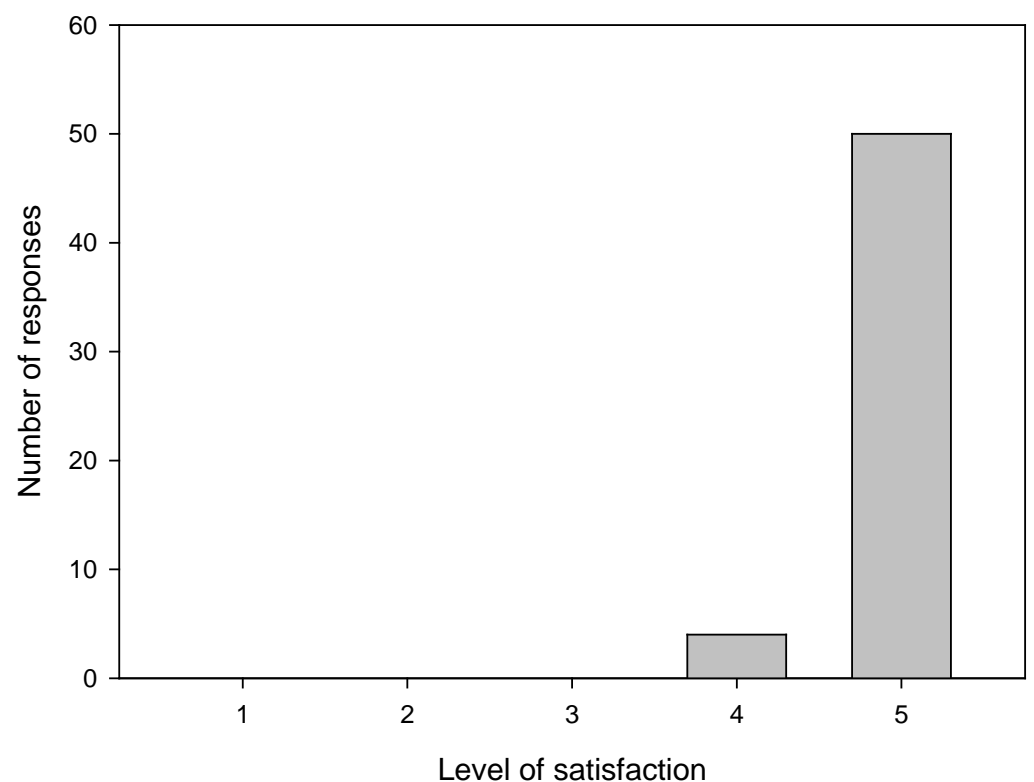

Figure 2. First question of the questionnaire. 
Rodríguez, J.; Castro-Rodríguez, E.; Sánchez-Pérez J.; Serrano-Martínez, J.

Did you learn something new?

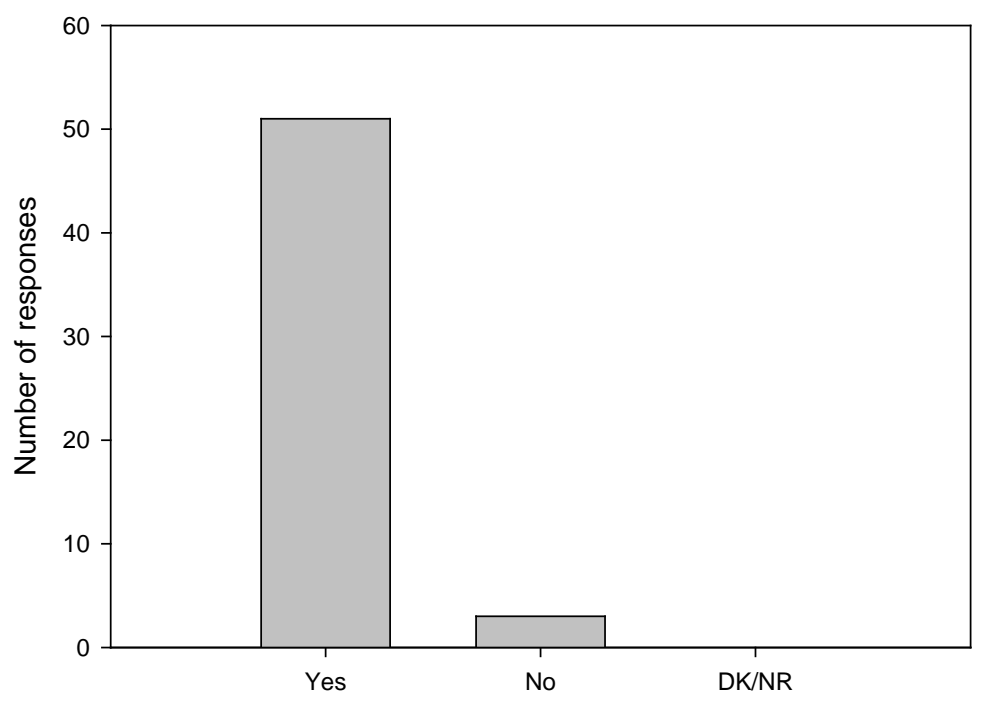

Figure 3. Second question of the questionnaire.

If the answer is yes, what did you learn?

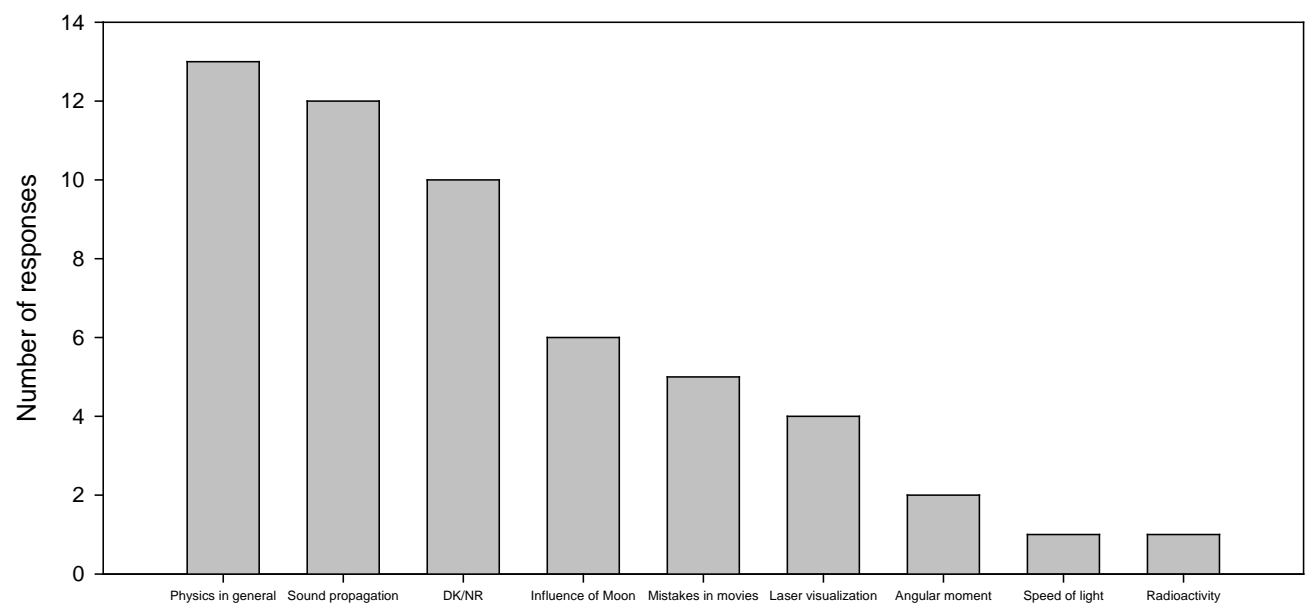

Figure 4. Third question of the questionnaire. 
UPCT-Bloopbusters: Teaching Science and Technology through Scene Movies and related Experiments

\section{Conclusions}

The educational project called 'UPCT-Bloopbusters' through which a group of professors of the UPCT, Spain, use science fiction movie scenes as well as different experiments within the lecture room to teach both physics and engineering technology has been presented. The results of a survey carried out among the students of a course in which such methodology was given show that the project was more than welcome while at the same time favored the learning of a great deal of physics and technology concepts.

\section{References}

Asimov, I. (1968). Try science fiction as a teaching aid, The Physics Teacher. 6, 416.

Barnett, M., Wagner, H., Gatling, A., Anderson J., Houle, M., \& Kafka, A. (2006). The Impact of Science Fiction Film on Student Understanding of Science. J Sci Educ Technol. 15, 179.

Berne, R. W. \& Schummer, J. (2005). Teaching Societal and Ethical Implications of Nanotechnology to Engineering Students Through Science Fiction. Bulletin of Science, Technology \& Society. 25 (6), 459-468.

Bixler, A. (2007). Teaching Evolution with the Aid of Science Fiction. The American Biology Teacher. 69. 337-340.

Blasco, P.G., Mônaco, C.F., De Benedetto, M.A., Moreto, G., \& Levites, M.R. (2010). Teaching Through Movies in a Multicultural Scenario: Overcoming Cultural Barriers Through Emotions and Reflection. Family Medicine. 42(1), 22-4.

Blasco, P. , Blasco, M. , Levites, M. , Moreto, G. \& Tysinger, J. (2011). Educating through Movies: How Hollywood Fosters Reflection. Creative Education, 2, 174-180.

Cavelos, J. (1999). The science of Star Wars. New York: St. Martin's Press.

Chandler M. D. (2002). Start Using "Hollywood Physics" in Your Classroom! The Physics Teacher, 40, 420.

Daley, B. (2004). A Project-Based Approach: Students Describe the Physics in Movies. The Physics Teacher, 42, 41.

Dark, M. L. (2005). Using Science Fiction Movies in Introductory Physics. The Physics Teacher, 43, 463.

Everitt, L. R. and Patterson, E. T. (1999). Electromagnetism in the movies. The Physics Teacher, 37, 511.

Fraknoi, A. (2002). Teaching Astronomy with Science Fiction: A Resource Guide. Astronomy Education Review, 1(2). 
Frieden, J. A. \& Elliott, D. W. (2007). Teach with movies: using the storytelling power of movies to motivate students. Teacher Librarian, 34 (3), 61.

Kakalios, J. (2005). The physics of superheroes. New York: Gotham Books.

Palacios, S. L. (2007). El Cine y la Literatura de Ciencia Ficción como Herramientas Didácticas en la Enseñanza de la Física: Una Experiencia en el Aula. Rev. Eureka. Enseñ. Divul. Cien., 4(1), 106-122.

Rogers, T. (2007). Insultingly Stupid Movie Physics: Hollywood's Best Mistakes, Goofs and Flat-Out Destructions of the Basic Laws of the Universe. Sourcebooks Hysteria.

Rose, C. (2003). How to teach biology using the movie science of cloning people, resurrecting the dead, and combining flies and humans. Public Understand. Sci. 12, 289-296.

Smith, D. A. (2009). Reaching Nonscience Students Through Science Fiction. The Physics Teacher, 47, 302.

Weiner, A. (2007). Don't Try This at Home! The Physics of Hollywood Movies. Kaplan, Inc.: New York.

Wolverton, M. \& Stern, R. (2002). The science of Superman. New York: i Books. 